This item was submitted to Loughborough's Research Repository by the author.

Items in Figshare are protected by copyright, with all rights reserved, unless otherwise indicated.

\title{
Effect of long term driving on driver discomfort and its relationship with seat fidgets and movements (SFMs)
}

PLEASE CITE THE PUBLISHED VERSION

http://dx.doi.org/10.1016/j.apergo.2016.05.009

PUBLISHER

Elsevier

VERSION

AM (Accepted Manuscript)

\section{PUBLISHER STATEMENT}

This work is made available according to the conditions of the Creative Commons Attribution-NonCommercialNoDerivatives 4.0 International (CC BY-NC-ND 4.0) licence. Full details of this licence are available at: https://creativecommons.org/licenses/by-nc-nd/4.0/

\section{LICENCE}

CC BY-NC-ND 4.0

\section{REPOSITORY RECORD}

Sammonds, George M., Mike Fray, and Neil J. Mansfield. 2019. "Effect of Long Term Driving on Driver Discomfort and Its Relationship with Seat Fidgets and Movements (sfms)". figshare.

https://hdl.handle.net/2134/22441. 


\title{
EFFECT OF LONG TERM DRIVING ON DRIVER DISCOMFORT AND ITS RELATIONSHIP WITH SEAT FIDGETS AND MOVEMENTS (SFMS)
}

\author{
Dr. George M Sammonds, Dr. Mike Fray \& Prof. Neil J Mansfield \\ Environmental Ergonomics Research Centre \\ Loughborough Design School \\ Loughborough University \\ Loughborough \\ Leicestershire, LE11 3TU \\ UK
}

\begin{abstract}
Discomfort in vehicle seats is a multifactorial problem with large increases in discomfort occurring during extended duration driving. Due to the nature of driver discomfort, previous research has found it difficult to accurately quantify long term driver discomfort via the use of objective measures. This paper reports a laboratory study that investigates a novel objective measure of long term driver discomfort and its correlation with subjective discomfort ratings. Analysis of driver's seat fidgets and movements was conducted over the duration of a 140 minute drive on a driving simulator in addition to collecting subjective ratings of discomfort. It is shown that as subjects' subjective discomfort increases, the frequency of subjects' seat fidgets and movements increases congruently. A large correlation is observed between the subjective and objective measures of driver discomfort and provides the opportunity for long term discomfort evaluations to be made via remote monitoring; removing the need for subjective assessment.
\end{abstract}

\section{Introduction}

In the automotive industry today, driver comfort has developed from being considered a luxury to a requirement. However, many cars are purchased with just a short consideration of comfort in the showroom (Mansfield, 2005). This can be misleading, as sitting in one posture for a prolonged duration will result in increased discomfort regardless of task and vibration exposure. Mansfield et al. (2014) and Mansfield et al. (2015) demonstrated that a 'showroom' or static analysis is not sufficient to asses a seat's comfort as it fails to encompass many of the other factors affecting overall car seat discomfort. Porter et al. (2003) demonstrated that short term evaluations of discomfort are inadequate as the effects of fatigue and long term sitting have not been accounted for.

Previous research has recommended that driving trials have a duration of at least 2 hours to accurately determine the performance of a seat (Gyi and Porter, 1999; Porter et al., 2003). Porter et al. (2003) demonstrated that although some seats are considered uncomfortable after 15 minutes, others that are initially considered comfortable become uncomfortable after about an hour; further highlighting the importance of long duration evaluation. Previous research into commercial vehicle driver discomfort has implemented trial durations ranging from 60 seconds to 135 minutes (Kolich, 2003a; Gyi and Porter, 1999), and findings demonstrate that temporal factors greatly influence driver discomfort as significant changes in overall discomfort have been observed at approximately 
80 - 110 minutes of driving (Gyi and Porter, 1998). This study intends to investigate a longer duration than previous research and also aims to encompass vibration, another important factor affecting driver discomfort (Mansfield et al., 2015).

Mansfield's 4 factor model of overall car seat discomfort (2014) (Figure 1) demonstrates that both vibration or 'dynamic factors' and temporal factors greatly influence driver discomfort and previous research has shown that as vibration significantly affects the onset of discomfort (Mansfield et al., 2015). Therefore it is essential not to disregard vibration or dynamic factors and ensure that all factors surrounding overall car seat discomfort are included in driving trials. This study aims to encompass all these factors by exposing participants to vibration levels as experienced whilst driving

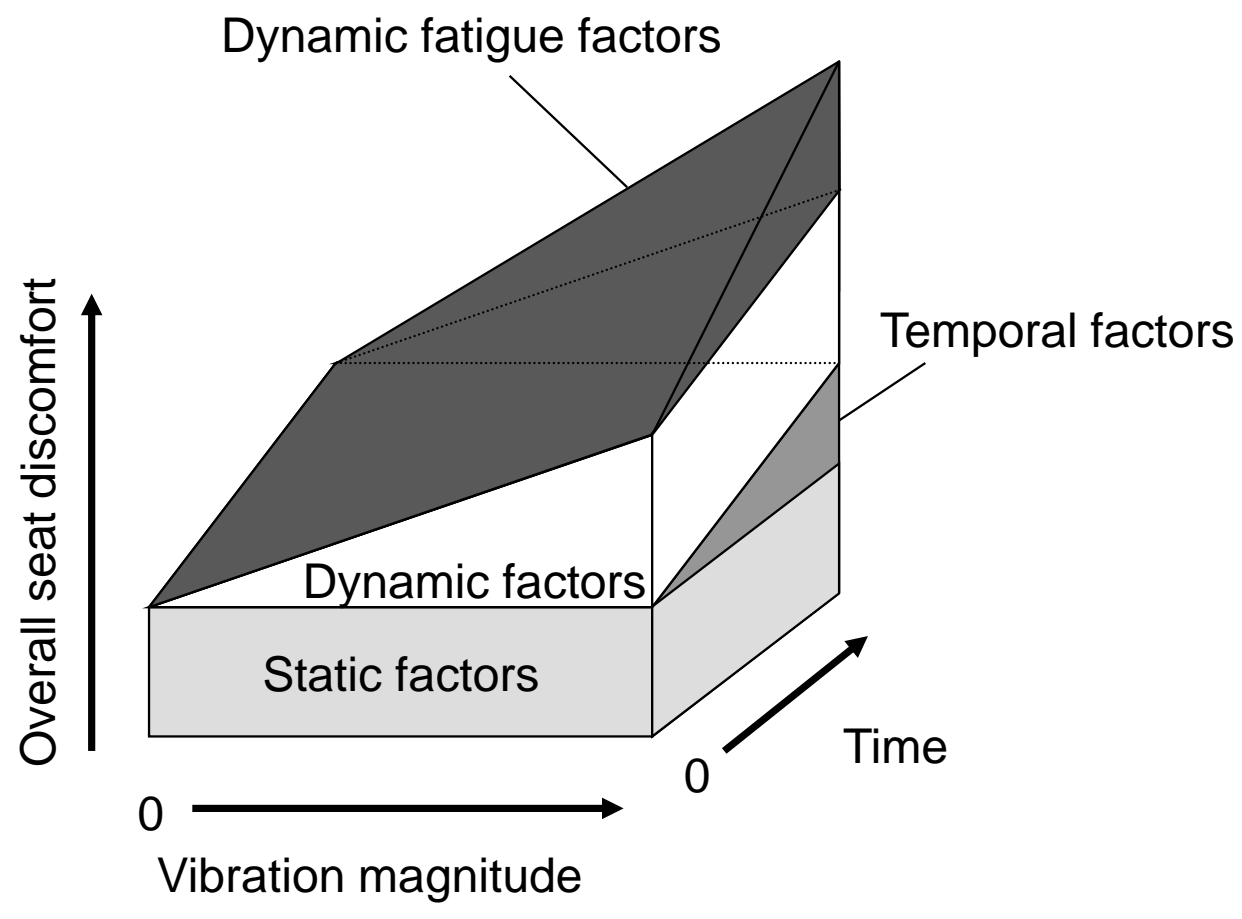

Figure 1: Updated 4 Factor Model of Overall Car Seat Discomfort including static, dynamic and temporal factors (Mansfield, 2014)

Another issue currently surrounding the automotive industry is how to accurately quantify overall car seat discomfort. Many different methods are in use across the field of driver discomfort, with varying levels of success, further complicating understanding of the concept (De Looze et al., 2003). Subjective measures of discomfort have been questioned as the validity of subjective measures relies on the ability of the subject to accurately describe their perceived discomfort level and a variety of extraneous factors can influence the subjects' choice (Hermann and Bubb, 2007). As a result, various objective measures have been implemented throughout the industry and these may hold some advantages over subjective measures (Le et al., 2014). However, successful objective measures are difficult to find in both the literature and practice (Zenk et al., 2012). 
One objective measure that has been successful in determining the effect of sitting in chairs on the body is a measure of In-Chair Movement (ICM). This is based on the principle that when a person first sits down they feel little discomfort and move little, however, over extended periods of sitting increasing discomfort has been shown to lead to significant increases in ICMs (Bendix et al., 1985; Jensen and Bendix, 1992; Fenety et al., 2000) and frequent ICMs have been associated with high sitting discomfort (Bhatnager et al., 1985; Fenety and Walker, 2002). People move unconsciously when seated, even when driving, with the purpose of relieving pressure of compressed body parts with impeded blood flow (Hermann and Bubb, 2007) and joint pressure (Hirao et al., 2006). This theory has been proven in much of the literature surrounding seating comfort. Jackson (2009) conducted a study where gilder pilots were shown to make large fidgeting movements after 40 minutes of sitting in order to relieve buttock pressure.

Other studies have determined the relationship between discomfort caused by prolonged sitting and fidgeting, stating that it can take up to 30 minutes for discomfort to reach a threshold where a behavioural response is required by the sitter (Sember, 1994) and that $29.7 \%$ of the variance in discomfort can be explained by postural movements (Tefler et al., 2009). Further studies have implemented the use of pressure mats to record the change in a subject's centre of pressure (COP) and found that the standard deviation of COP can be correlated to discomfort ( $\mathrm{Na}$ et al., 2005; Søndergaard et al., 2010). However many issues have been highlighted with the use of pressure mats whilst assessing the comfort of a seat (Gyi and Porter, 1999) and few researchers have included a driving task in their investigations.

If a measure of movement that focuses on vehicle seats can be implemented into the automotive industry, such a finding creates the opportunity to less subjectively measure a subjects' perceived discomfort and opens the door for measurements to be made by remote monitoring.

\section{Aims and Objectives}

The purpose of this study is to investigate an objective measure of discomfort via the analysis of fidgets and movements in a car seat and to draw a comparison with subjective discomfort ratings. The ultimate aim is to produce an objective measure to replace subjective assessment. Seat Fidgets and Movements (SFMs) will be studied. The research hypotheses of this study are:

- SFM frequency will increase with duration of driving.

- SFM magnitude will increase with duration of driving.

- A relationship will be observed between subjective discomfort ratings and SFMs 


\section{Methodology}

\subsection{Sample \& Design}

10 Participants, consisting of 6 males and 4 females, from the local area and student population of Loughborough University were recruited to participate in a laboratory study. Participants were aged between 22 and 34 (Mean = 26) and all held a full driving license to ensure that posture and task required during the study would be familiar. Furthermore, participants were only recruited if they had been driving regularly in the year prior to the study.

Each trial consisted of 140 minutes continuous driving on the driving simulator housed at Loughborough University. All trials were conducted over the same time period, beginning at 10:00am, in order to control their initial discomfort level, as discomfort has been shown to increase throughout the duration of the day (Bazley et al., 2015). Participants were required to provide subjective discomfort ratings verbally every 10 minutes via the use of a 2 part questionnaire (Figure 2). Participants were trained in the use of the questionnaire prior to participation in the study and the rating scales were positioned in the participants' field of vision whilst driving. The questionnaire was a 2 stage process; with Part 1 focusing on local discomfort and Part 2 focusing on overall discomfort. Part 1 of the questionnaire includes the 6 point discomfort scale defined in ISO 2631-1 (2003) and part 2 utilises a newly developed overall discomfort rating scale adapted from the Borg CR100 scale (Borg \& Borg, 2002). This rating scale proved to be more successful in pilot studies and during another study (Mansfield et al., 2015) than other discomfort scales as it provides participants with a wider range of responses and allowed for subtle changes in discomfort. Part 1 of the questionnaire was used as a primer for part 2, encouraging subjects to systematically consider their discomfort across all body parts. 


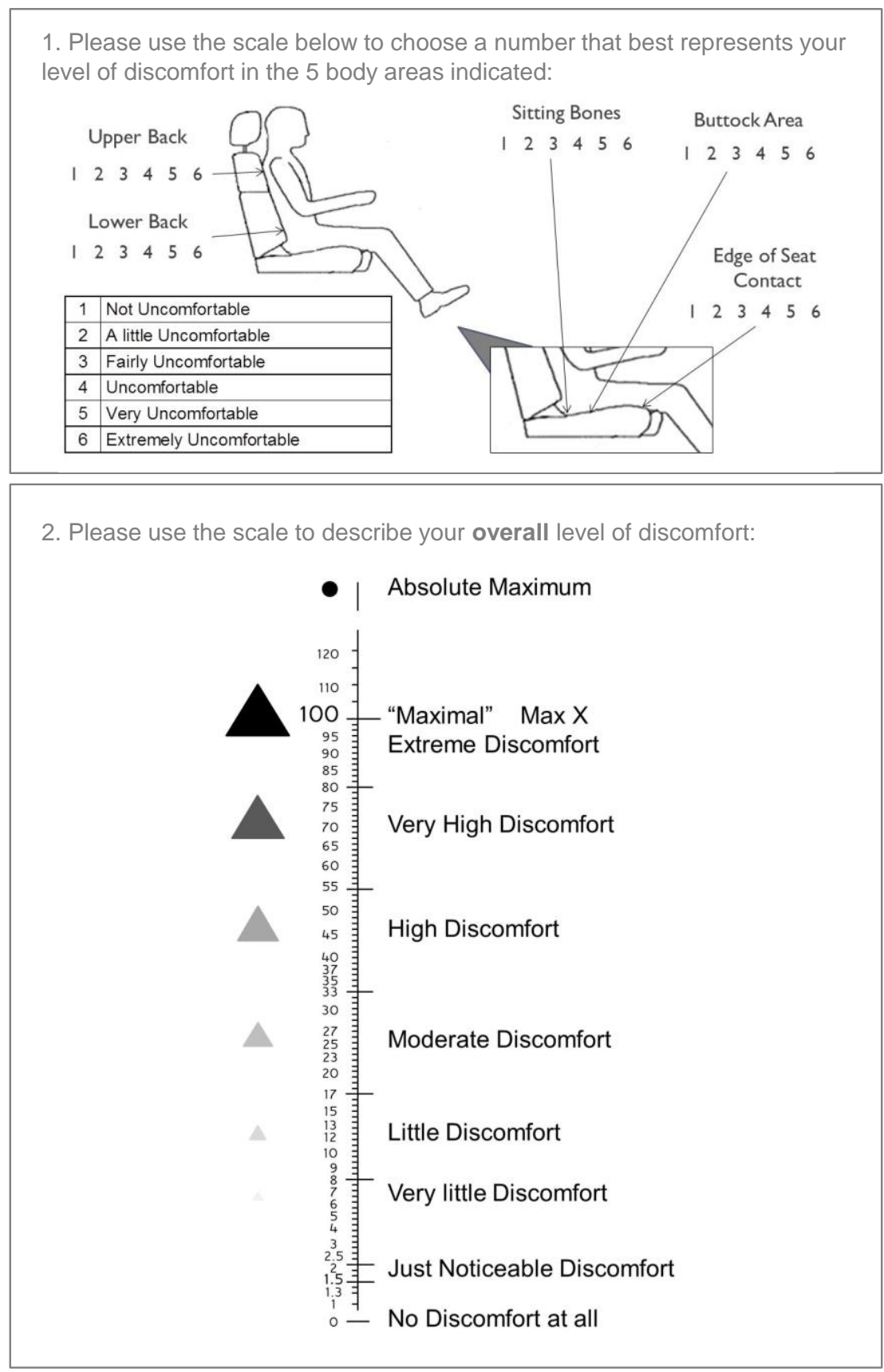

Figure 2: Questionnaire design showing part 1; including the discomfort scale defined in ISO 2631-1 and a description of the body parts analysed, and part 2; including the adapted Borg CR100 scale (Borg and Borg, 2002)

\subsection{Equipment}

Vibration exposure was simulated using the Rexroth Hydraudyne B.V Micro Motion 600-6DOF-200MK5 multi-axis vibration simulator (MAVIS) located at Loughborough University. Subjects were exposed to multi-axis vibration with an average total magnitude of $0.246 \mathrm{~m} / \mathrm{s}^{2}$ weighted r.m.s. The vibration was a replay of a recording of 6-dof motion at the floor of a car driving on a rough city road and was adjusted to represent a similar experience to a normal drive in the UK. System 
characterisation was also conducted for each subject as to ensure each subject experienced a similar exposure; within $10 \%$ of the desired magnitude.

Other environmental factors that were monitored and controlled during the experiment were noise and the thermal conditions of the laboratory, as both have been shown to have a large influence on seating comfort perception (Mellert et al., 2008; Hodder, 2013). Temperature $\left({ }^{\circ} \mathrm{C}\right.$ ) and humidity (RH\%) were monitored using a Solex SE126 Digital Humidity / Temperature Meter and although thermal conditions were not actively controlled, it was ensured that participants experienced thermal conditions within a 10\% range. Two Mackie Thump TH-15A two-way powered loudspeakers produced the noise associated with the driving simulator and volume was controlled so that it remained constant for each participant.

A production car seat frame accompanied by a production seat foam cushion were provided by a manufacturer. A rig was manufactured that housed the seat, steering wheel and pedals used to control the driving simulator (Figure 3). This rig replicated dimensions from a current production vehicle and a production steering wheel was used. Participants were directed along a standardised route throughout the drive on the simulator, via the use of audio prompts from a GPS navigation simulation.

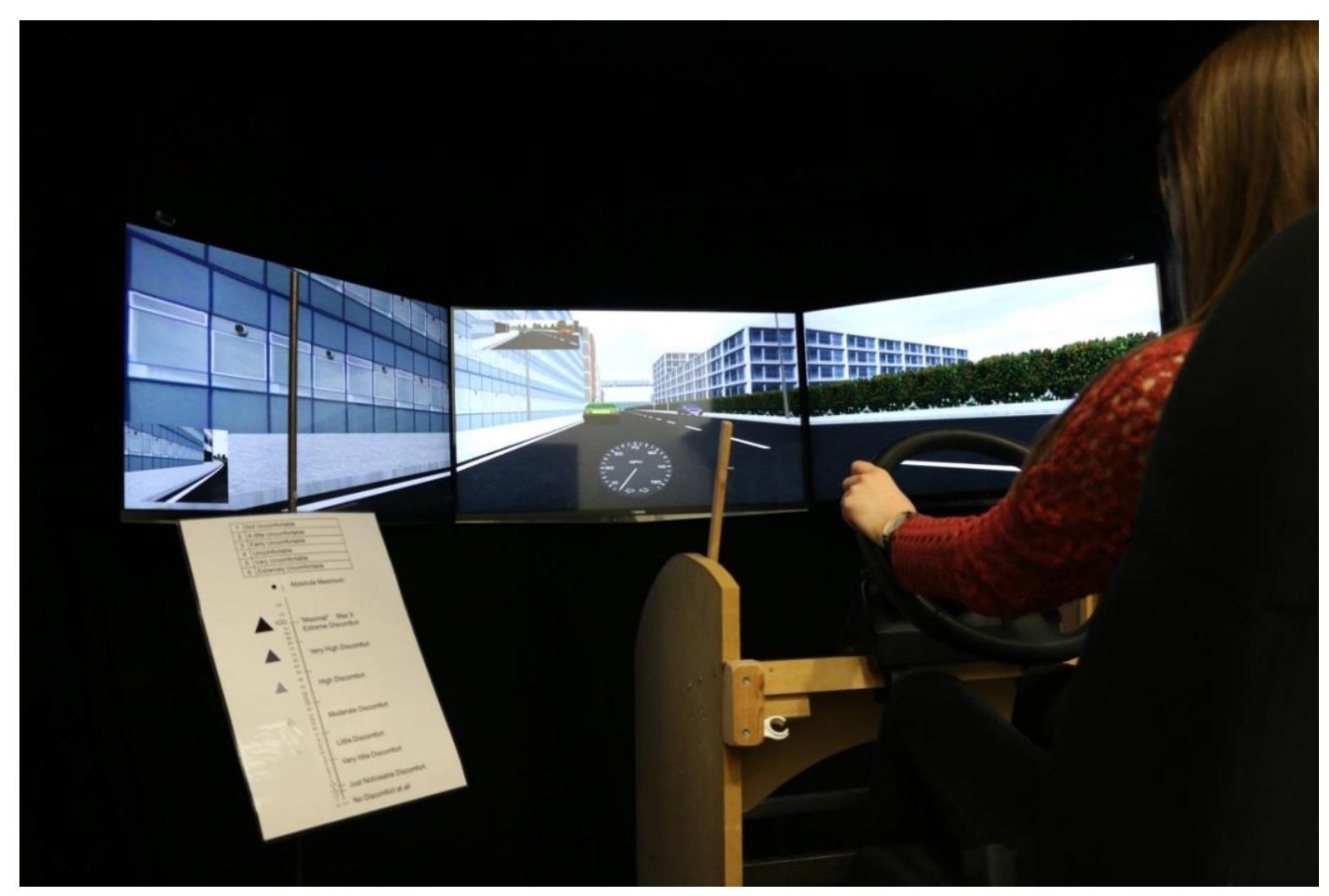

Figure 3: Driving simulator configuration 


\subsection{Seat Fidgets and Movements}

In addition to the 2 part subjective discomfort questionnaire, this study aimed to measure seat fidgets and movements (SFMs). Participants were video recorded to allow the investigator to analyse SFMs post trial. A Microsoft HD (1080p) webcam was positioned at approximately 45 degrees from the subject that provided the experimenter with a full body recording of the subject throughout the duration of the trial and allowed the experimenter to analyse and report any fidgets and movements the subject may make.

In order for this to be successful, it was necessary to develop a framework for reporting SFMs, outlining the definition of an SFM and which type of SFM this was in terms of magnitude. Therefore, the time at which the SFM occurred and the type of SFM were noted by the investigator post trial. SFM types were defined as:

- Type 1 - any movement of the limbs not related to the driving task (excluding transition from one hand to two on the steering wheel and any rubbing/scratching of the face etc.).

- Type 2 - any movement of the torso not related to the driving task.

- Type 3 - any movement of the whole body not related to the driving task.

\section{Results}

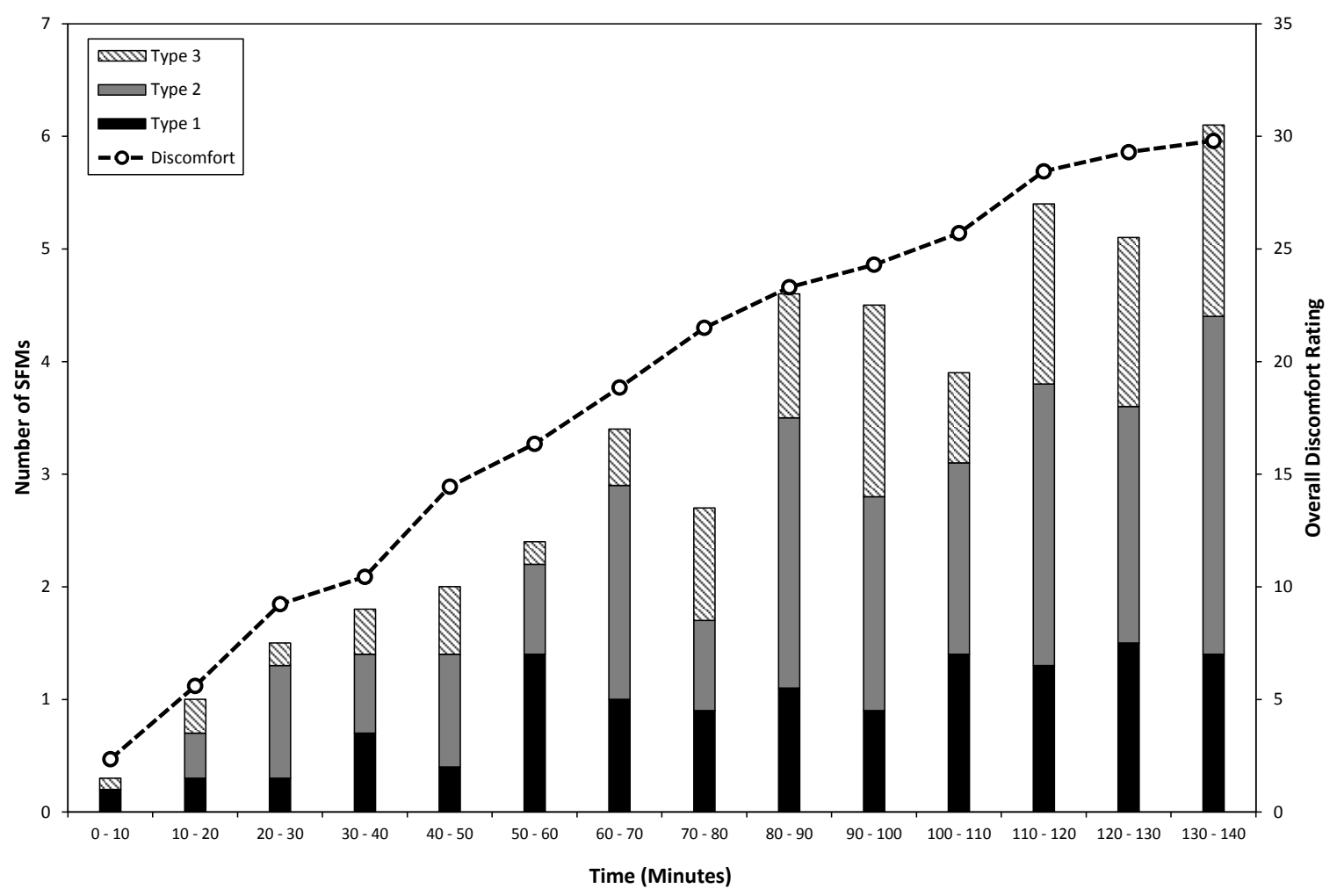

Figure 4: Mean Overall Discomfort Rating and Number of SFMs against time for all participants 
As expected, the overall discomfort rating increased over time (Figure 4). This occurred of each subject (Figure 5). SFMs are described by type to coincide with the definitions stated previously.

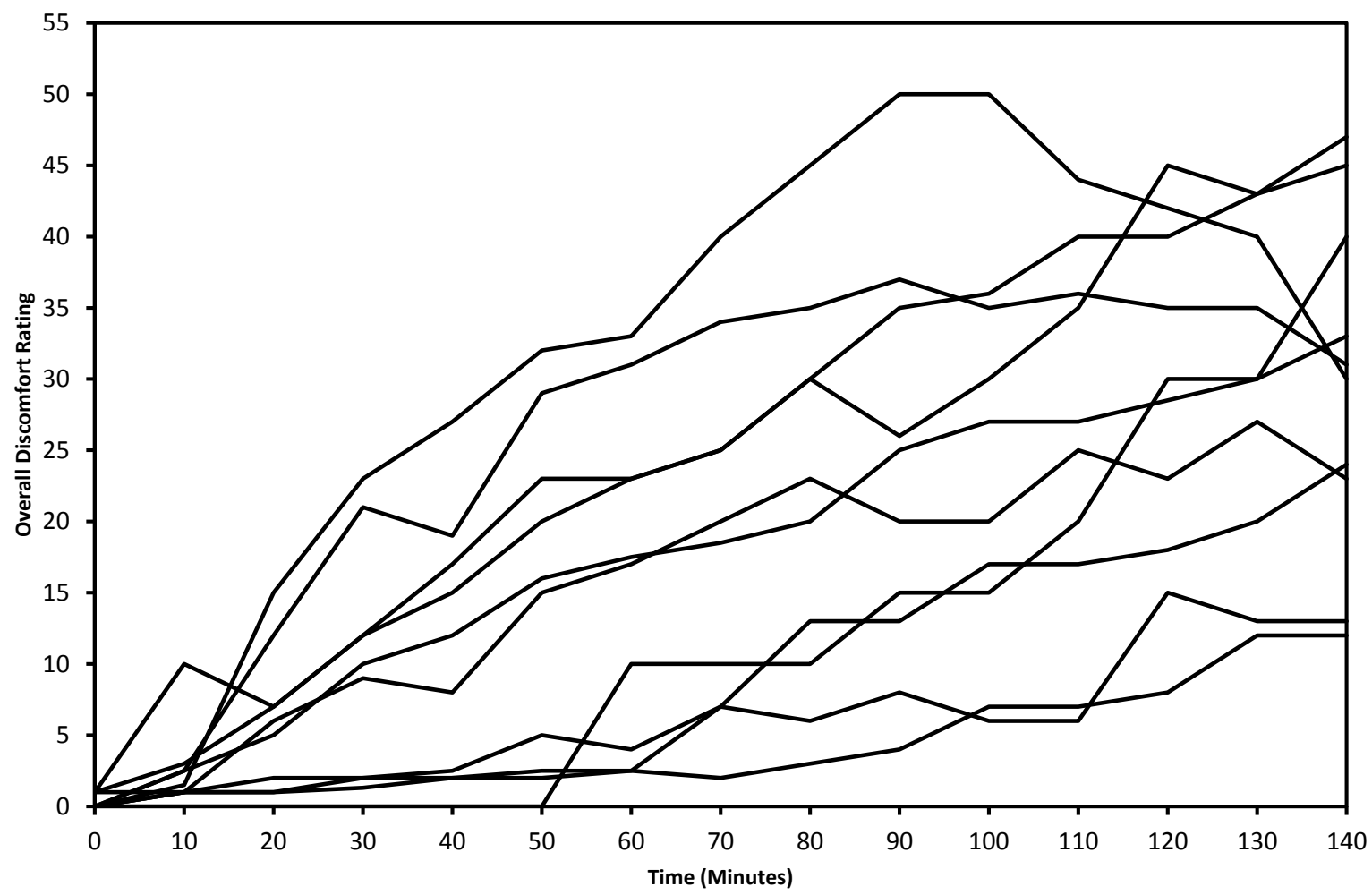

Figure 5: Overall Discomfort Rating over time for individual subjects

Both overall discomfort and SFM frequency, the number of SFMs per 10 minutes, are shown to increase with duration of driving and a close relationship is observed between SFM frequency and Overall Discomfort Ratings.

Participants mean overall discomfort rating increased from 2.35 after the first 10 minutes of driving to 29.8 upon completion of the trial. Participants' mean overall discomfort rating did not decrease at any time interval during the trial, showing that on average, overall discomfort increases with driving duration. Participants recorded a wide range of discomfort ratings across the duration of the trial and may be a result of individual susceptibility to discomfort and vibration exposure or as a result of interpretation of the discomfort scale. However all participants recorded an increase in overall discomfort throughout the duration of the trial and it is important to compare these findings with the findings for SFM measurements.

Participants' SFM frequency is also shown to increase across the duration of the trial. Participants recorded on average, 0.3 SFMs during the first 10 minutes of the trial, in comparison with 6.1 SFMs 
during the last 10 minutes of the trial. The results follow a similar trend to that observed for the participants' mean overall discomfort ratings (Figure 4).

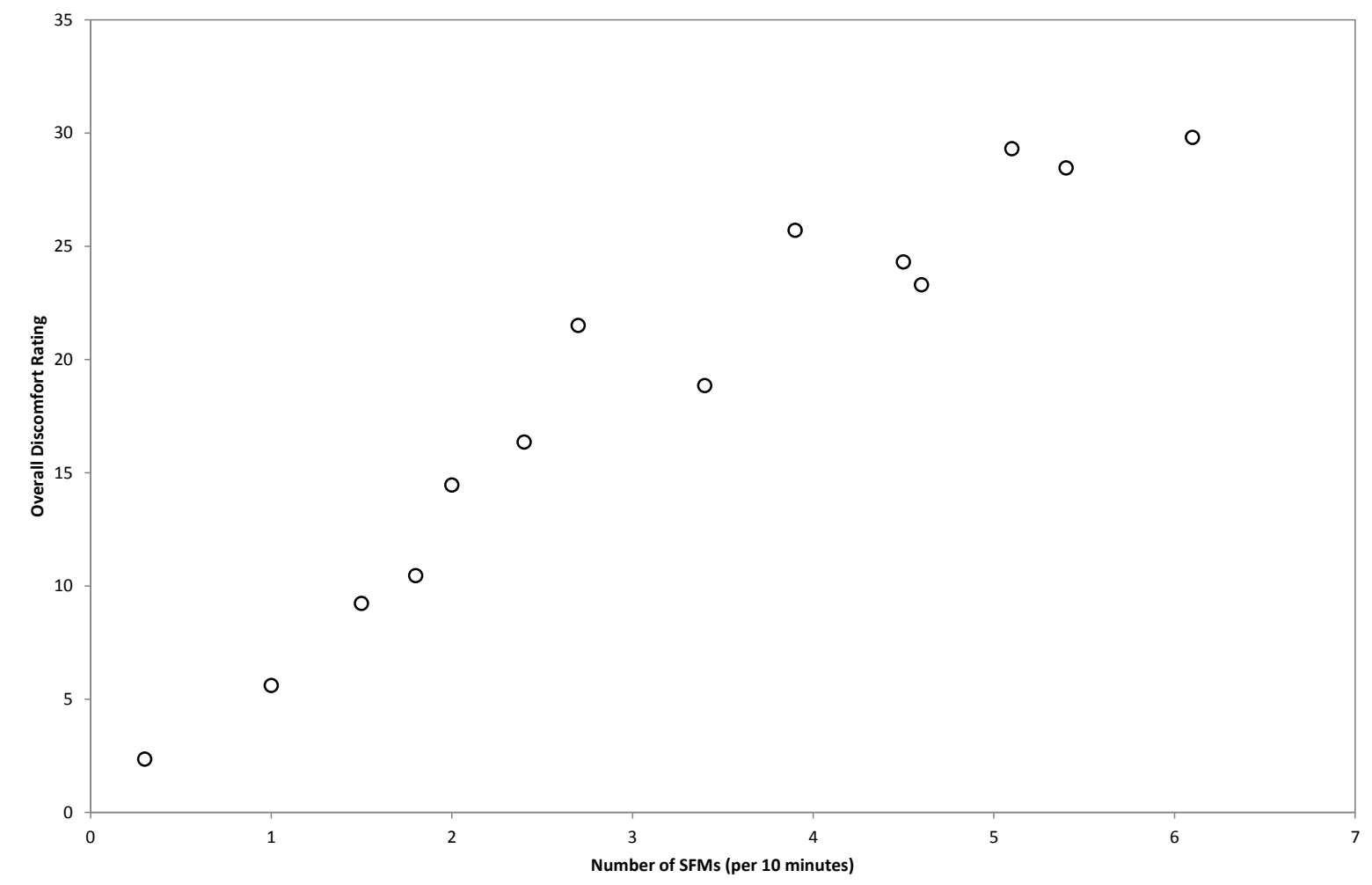

Figure 6: Scatter graph displaying average Number of SFMs against average Overall Discomfort Rating When comparing the results reported for overall discomfort and the SFM data recorded, it is clear that a close relationship exists. There is a positive relationship between the mean overall discomfort rating at each time interval and the number of SFMs recorded in the 10 minutes that preceded it; therefore it can be concluded that as overall discomfort increases, the frequency of SFMs also increases (Figure 6).

\section{Discussion}

\subsection{SFM Frequency}

The first research hypothesis was that SFM frequency would increase with duration of driving. The results show that both overall discomfort and the frequency of SFMs increases with time, supporting the studies by Bendix et al. (1985), Jensen and Bendix (1992) and Fenety et al. (2000). The statement by Hermann and Bubb (2007) that drivers move unconsciously in order to relieve pressure on compressed body parts suggests that people move or fidget in the seat when discomfort reaches a detection threshold. As the frequency of SFMs increases with time, this implies that as the duration of sitting increases drivers reach the detection threshold faster (Figure 7). 
A driver's detection threshold can be described as a driver's acceptable comfort level. As discomfort reaches the threshold and becomes detectable to the driver, the driver moves in the seat in order to relieve himself or herself of discomfort; therefore an SFM occurs. With extended duration driving, the driver's acceptable comfort level, or detection threshold decreases. Therefore discomfort reaches the detection threshold with increasing frequency and drivers record more frequent SFMs as time increases.

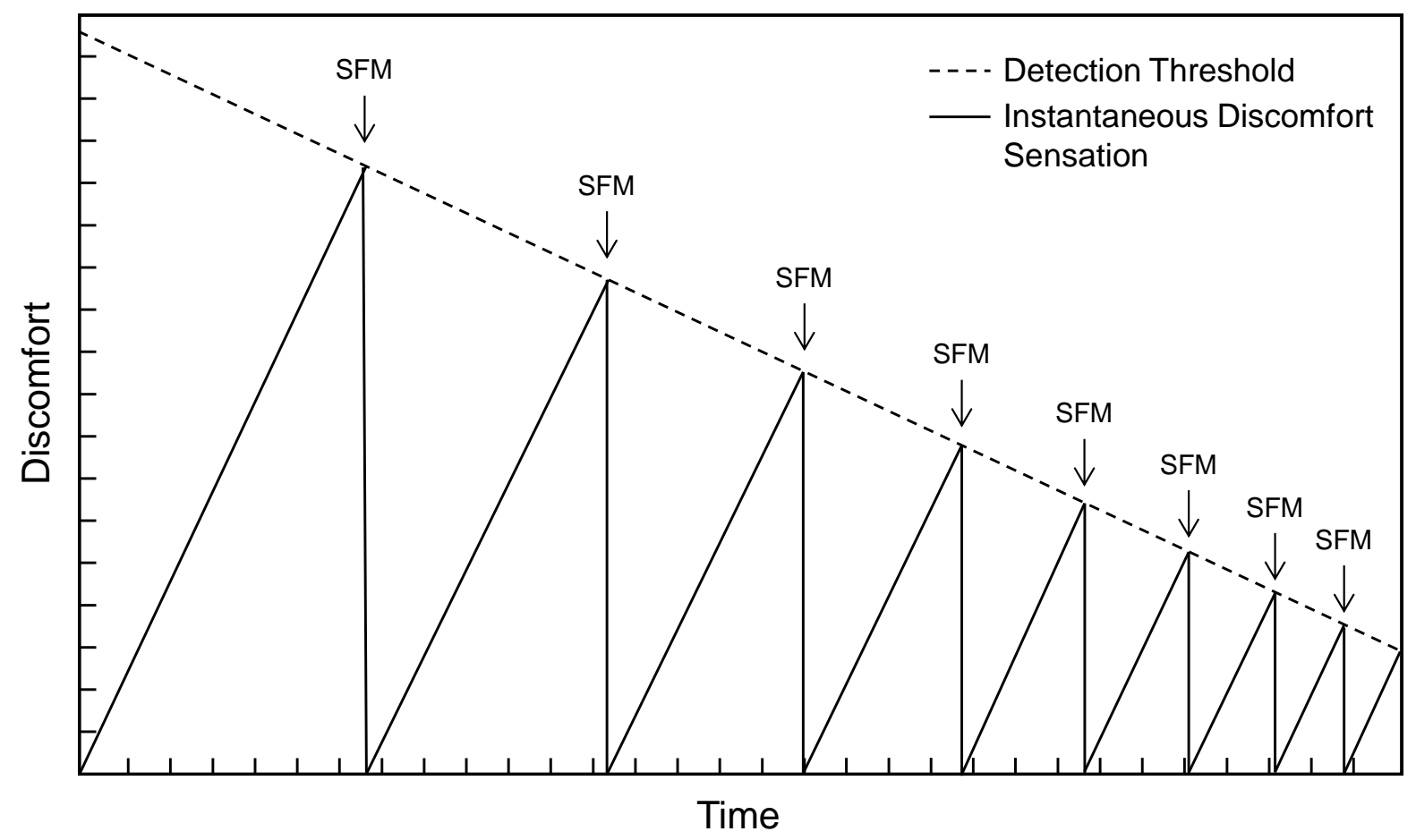

Figure 7: Conceptual model describing the occurrence of SFMs with duration of sitting

Previous research has suggested that it takes at least 30 minutes for discomfort to become sufficient for a behavioural response to occur (Sember, 2009) and this study supports this theory as, on average, participants first recorded more than 1 SFM per 10 minutes during the $20-30$ minute interval. However, some individual participants recorded 2 SFMs during the $10-20$ minute interval in addition to 1 participant recording 2 SFMs during the first 10 minutes of driving. This may suggest that the number of movements recorded may be a direct result of the driver's perceived discomfort level rather than a product of the duration spent driving.

\subsection{SFM Magnitude}

The second research hypothesis was that SFM magnitude would increase with duration of driving. Each SFM type related to a different magnitude of movement, Type 1 being a small movement and Type 3 being a large movement. 
The percentage of Type 2 and Type 3 SFMs did not increase with time (Figure 8). Two-way ANOVAs $(p=0.05)$ were conducted that compared the percentage of each SFM type at each time interval. No significant difference was found between percentage of Type 2 or 3 SFMs at the beginning of the trial and at the end. Therefore the conclusion can be drawn that SFM magnitude did not increase with duration of driving.

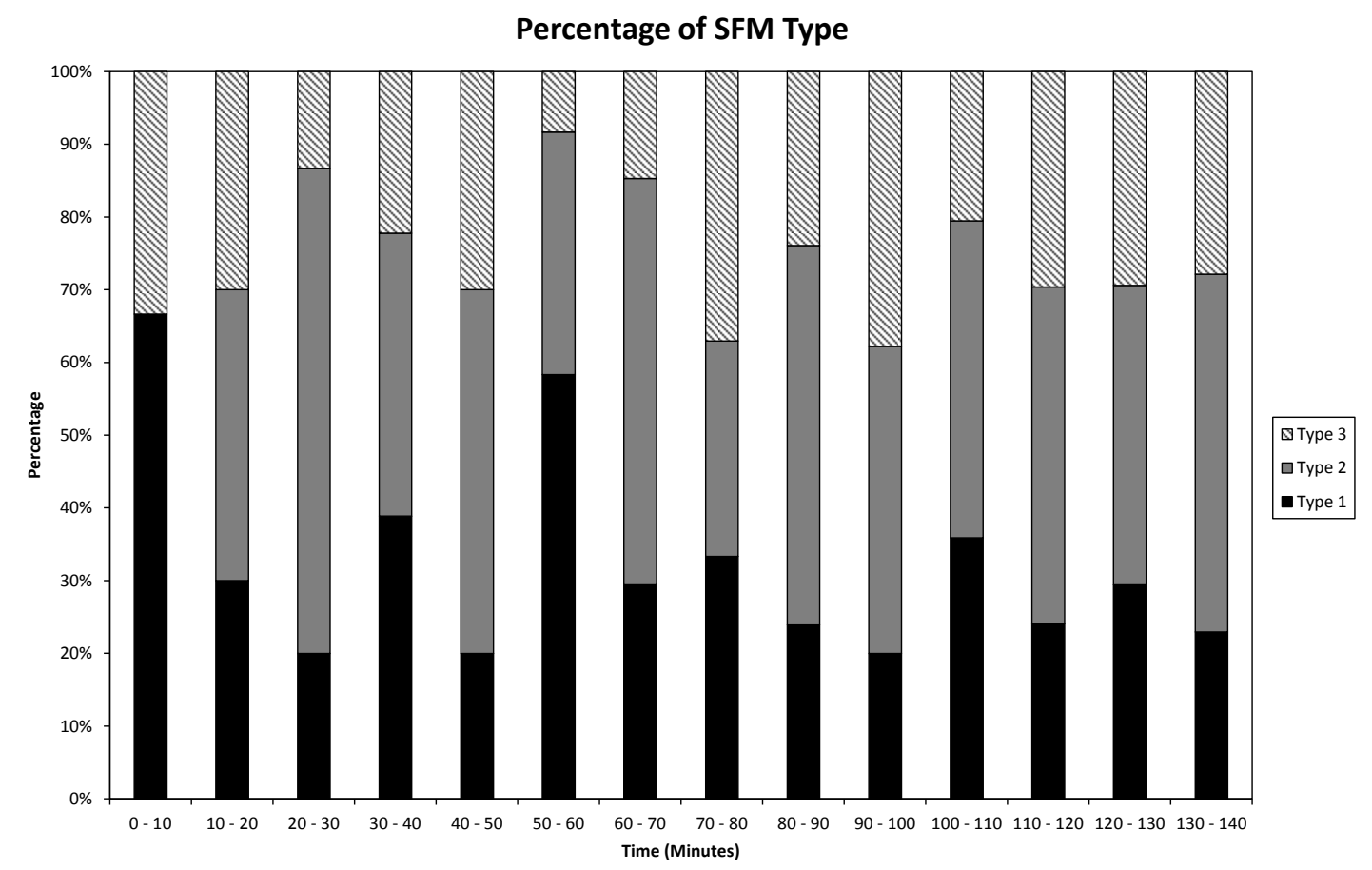

Figure 8: Graph describing changes in SFM type against time.

\subsection{Relationship between Overall Discomfort Rating and Total SFM Frequency}

It can clearly be seen from the results (Figure 4) that both overall discomfort and Total SFM frequency increase with time, however the final and most important aim of this study is to describe the relationship between overall discomfort and SFMs. A Pearson Correlation was performed on the data that compared the mean overall discomfort ratings and the mean number of SFMs per 10 minutes and a large positive correlation was found with an $r^{2}$ value of 0.927 and was therefore significant, suggesting that a strong relationship can be observed between overall discomfort and Total SFM frequency.

The overall aim of this study was to develop an objective measure that can be used to predict discomfort; a linear regression was performed to produce the equation:

$$
\Psi=3.002+48.68 m
$$

Where: $\Psi$ is the rating of overall discomfort and $\mathrm{m}$ is the number of SFMs per min. 
This equation was used to produce predicted values of discomfort using only SFM data, a comparison of the observed Overall Discomfort ratings and the predicted Overall Discomfort ratings can be seen in Figure 9.

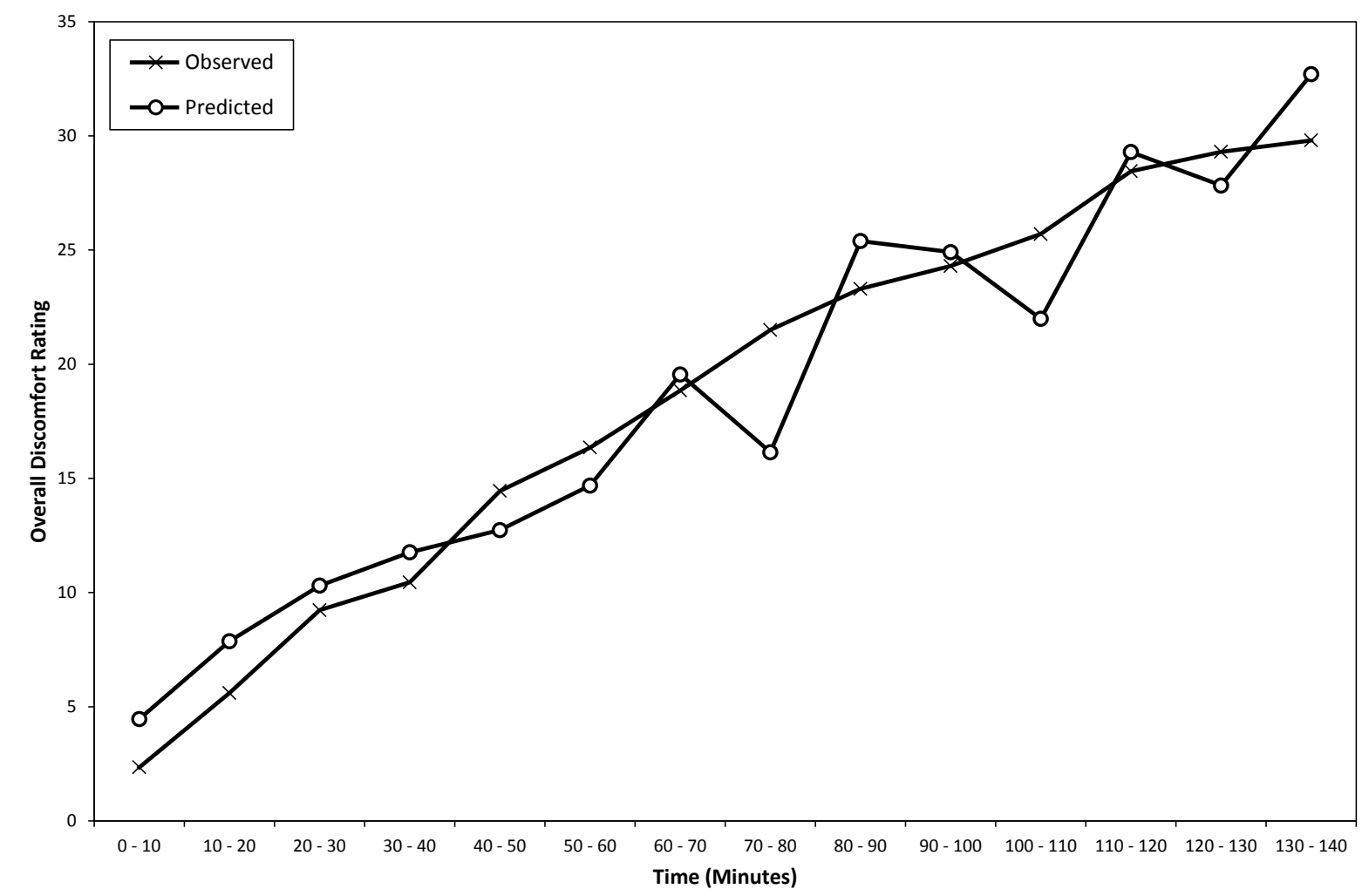

Figure 9: Observed vs. predicted overall discomfort using regression equation

As shown in Figure 9, the predicted values of discomfort are closely related to the observed values suggesting that for the data in this experiment, SFM observations can be used to accurately predict subjective overall discomfort ratings. This supports the study conducted by Telfer et al. (2009) whereby $29.7 \%$ of the variance in discomfort could be explained by postural movements and further verifies that movements made by drivers can be closely correlated with subjective discomfort perception.

\subsection{Relationship between SFMs and Verbal Discomfort Descriptors}

As the overall objective of this study was to provide an objective measure of discomfort that could be implemented into the automotive industry with the aim of replacing subjective methods of discomfort assessment, it was important to understand how SFM data relates to verbal discomfort descriptors. Therefore for each 10 minutes a verbal discomfort descriptor was chosen, using the discomfort scale (Figure 2), which related to the Overall Discomfort score and this in turn, was matched with the total number of SFMs per minute for that 10 minute period (Table 1). 


\begin{tabular}{|r|r|r|r|}
\hline Time & Discomfort Score & Number of SFMs (per min) & Descriptor \\
\hline 10 & 2.35 & 0.03 & Just Noticeable Discomfort \\
20 & 5.6 & 0.1 & Very Little Discomfort \\
30 & 9.23 & 0.15 & Very Little Discomfort \\
40 & 10.45 & 0.18 & Little Discomfort \\
50 & 14.45 & 0.2 & Little Discomfort \\
60 & 16.35 & 0.24 & Little Discomfort \\
70 & 18.85 & 0.34 & Little-Moderate Discomfort \\
80 & 21.5 & 0.27 & Little-Moderate Discomfort \\
90 & 23.3 & 0.46 & Moderate Discomfort \\
100 & 24.3 & 0.45 & Moderate Discomfort \\
110 & 25.7 & 0.39 & Moderate Discomfort \\
120 & 28.45 & 0.54 & Moderate-High Discomfort \\
130 & 29.3 & 0.51 & Moderate-High Discomfort \\
140 & 29.8 & 0.61 & Moderate-High Discomfort \\
\hline
\end{tabular}

Table 1: Table showing comparison of number of SFMs per minute with discomfort score and discomfort descriptors.

Using the equation produced by the regression analysis another table was produced describing the range of number of SFMs and Overall Discomfort score against the verbal discomfort descriptors. This can be seen in Table 2.

\begin{tabular}{|r|r|r|}
\hline Discomfort Score & Number of SFMs (per min) & Descriptor \\
\hline 0 & 0 & No Discomfort at all \\
$0-4$ & $0-0.021$ & Just Noticeable Discomfort \\
$4-10$ & $0.021-0.144$ & Very Little Discomfort \\
$10-17$ & $0.144-0.288$ & Little Discomfort \\
$17-23$ & $0.288-0.411$ & Little - Moderate Discomfort \\
$23-28$ & $0.411-0.514$ & Moderate Discomfort \\
$28-33$ & $0.514-0.616$ & Moderate - High Discomfort \\
$33+$ & $0.616+$ & High Discomfort \\
\hline
\end{tabular}

Table 2: Table outlining No of SFMs (per $\mathrm{min}$ ) and the relationship with discomfort scores and discomfort descriptors.

Table 2 suggests that a driver experiencing very little discomfort would record an SFM less than once every 7 minutes whereas a driver experiencing moderate-high discomfort would record an SFM once every 2 minutes. There is need for this method to be tested against new data, however when fitting to the data in this experiment, the SFM method serves to successfully replace subjective ratings of overall discomfort and can be utilised to provide a verbal description of discomfort. This may allow 
for discomfort measurements to be made remotely, requiring very little contact with the subject in a less invasive way than many of the other objective measures suggested by the literature (Le et al., 2014) and in a way that does require the properties of the seat to be altered by using equipment such as pressure mats (Na et al., 2005; Søndergaard et al., 2010).

Currently the design of the method requires a human observer to distinguish which movements are task related or a result of the dynamic environment of the vehicle and which movements are discomfort related and therefore recorded as an SFM. Consequently this adds an aspect of subjectivity to the current method. Future research should aim to eliminate the observer by developing a technological approach that can perform the same task as the human observer. If this can be successfully accomplished, it provides the opportunity for the method to be implemented autonomously, recording discomfort remotely with very little impact on the subject, something that may be extremely useful to the automotive industry.

\subsection{Limitations of the Study}

The major limiting factor of the method is that although it has been shown to be very successful on a group level, more will work will need to be conducted in order to determine the application of the method with regards to the individual. The results of this study suggest that although the method can be extremely reliable at a group level and for certain participants when recording SFMs over intervals (per 10 minutes), further analysis has suggested that an accumulative approach may be more appropriate for fitting the method on an individual level. Further work will need to be conducted in order to determine whether the method will need to be adapted or whether improvements at the individual level will be observed with a larger sample.

This is another major limitation of the study as this study was conducted with a relatively small sample $(n=10)$ of a very particular demographic. In order to for the method to be successful it will need to be tested with a wider range of ages and anthropometry as the majority of participants tested were between the ages of 20 and 30. Previous research has shown that older drivers are more susceptible to discomfort (Meng and Siren, 2012) and this may impact the success of the SFM method.

In order to develop the method further, it will need to be tested in the field as well as in a laboratory environment. Some aspects of the driving simulator such as the visual output and the fact that the motion produced by the motion platform does not include outside forces (acceleration, deceleration and cornering), although sufficient for laboratory testing, do not completely represent a realistic driving environment. Trials conducted in the field will allow for an examination of the method 
against real world driving conditions, a factor that may be crucial in determining the success of the method for use in the automotive industry.

\section{Conclusion}

Ultimately, the results of the laboratory study show that a measure of SFMs can successfully be used to predict subjective overall car seat discomfort. Fitting to the data in this experiment, a strong correlation was found between predictions of discomfort made using SFM data and observed subjective overall discomfort. Further studies will need to validate the method further however there is the possibility for discomfort analysis to be made by remote monitoring as SFM measurements have been found to successfully replace subjective discomfort analysis.

Future work should aim to validate the methodology and further determine the relationship between overall driver discomfort and driver seat fidgets and movements. The method should be tested in different laboratory conditions with different vibration stimuli to determine whether the same correlation is observed with a different discomfort gradient.

Furthermore, the relationship between SFM magnitude and overall discomfort should be further investigated as no correlation was observed during this experiment; however, this may be due to the design of the method as magnitude was defined by the type of movement. If a method of measuring the magnitude of every movement in terms of distance and duration, regardless of type, could be implemented there is a chance that very different results may be observed and a relationship may be seen between SFM magnitude and driving duration.

If this method is proved to be successful in further studies, it provides the opportunity for the SFM method to replace subjective assessments of discomfort in drivers. This would eliminate the issues regarding subjective assessment and furthermore, allow measurements of discomfort to be made simply and effectively with no contact with the driver. Such a finding would allow for major changes to made to the methods used for discomfort assessment in drivers and improve the success of future research.

\section{References}

Bazley, C., Nugent, R., \& Vink, P. (2015). Patterns of Discomfort. Journal of Ergonomics, 5 (1). http://dx.doi.org/10.4172/2165-7556.1000136

Bendix, T., Winkel, J., \& Jessen, F. (1985). Comparison of office chairs with fixed forwards or backwards inclining, or tiltable seats. European Journal of Applied Physiology and Occupational Physiology, 54 (4), 378-385. 
Bhatnager, V., Drury, C. G., \& Schiro, S. G. (1985). Posture, postural discomfort, and performance. Human Factors: The Journal of the Human Factors and Ergonomics Society, 27 (2), 189-199.

Borg, E., \& Borg, G. (2002). A comparison of AME and CR100 for scaling perceived exertion. Acta Psychologica, 109 (2), 157-175.

De Looze, M. P., Kuijt-Evers, L. F., \& Van Dieën, J. A. A. P. (2003). Sitting comfort and discomfort and the relationships with objective measures. Ergonomics, 46 (10), 985-997.

Fenety, P. A., Putnam, C., \& Walker, J. M. (2000). In-chair movement: validity, reliability and implications for measuring sitting discomfort. Applied Ergonomics, 31 (4), 383-393.

Fenety, A., \& Walker, J. M. (2002). Short-term effects of workstation exercises on musculoskeletal discomfort and postural changes in seated video display unit workers. Physical Therapy, 82 (6), 578589.

Gyi, D. E., \& Porter, J. M. (1999). Interface pressure and the prediction of car seat discomfort. Applied Ergonomics, 30 (2), 99-107.

Hermann, S., \& Bubb, H. (2007). Development of an objective measure to quantify automotive discomfort over time. In Industrial Electronics, 2007. ISIE 2007. IEEE International Symposium on (pp. 2824-2830). IEEE.

Hirao, A., Kitazaki, S., \& Yamazaki, N. (2006). Development of a New Driving Posture Focused on Biomechanical Loads (No. 2006-01-1302). SAE Technical Paper.

Hodder, S. (2013). Thermal Environments and Vehicles. In: Automotive Ergonomics: Driver-vehicle interaction. Florida: CRC Press, 97-121.

Jensen, C. V., \& Bendix, T. (1992). Spontaneous movements with various seated-workplace adjustments. Clinical Biomechanics, 7 (2), 87-90.

Kolich, M. (2003). Automobile seat comfort: occupant preferences vs. anthropometric accommodation. Applied Ergonomics, 34 (2), 177-184.

Le, P., Rose, J., Knapik, G., \& Marras, W.S. (2014). Objective classification of vehicle seat discomfort. Ergonomics, 57 (4), 536-544.

Mansfield, N. 2005. Human Response to Vibration. CRC Press 
Mansfield, N., Mackrill, J., Rimell, A. N., \& MacMull, S. J. (2014). Combined effects of long-term sitting and whole-body vibration on discomfort onset for vehicle occupants. ISRN Automotive Engineering, http://dx.doi.org/10.1155/2014/852607, 2014.

Mansfield, N., Sammonds, G., \& Nguyen, L. (2015). Driver discomfort in vehicle seats - Effect of changing road conditions and seat foam composition, Applied Ergonomics, 50, 153-159.

Mellert, V., Baumann, I., Freese, N., \& Weber, R. (2008). Impact of sound and vibration on health, travel comfort and performance of flight attendants and pilots. Aerospace Science and Technology, $12,18-25$.

Meng, A., \& Siren, A. (2012). Cognitive problems, self-rated changes in driving skills, driving-related discomfort and self-regulation of driving in old drivers. Accident Analysis \& Prevention, 49, 322-329.

Na, S., Lim, S., Choi, H. S., \& Chung, M. K. (2005). Evaluation of driver's discomfort and postural change using dynamic body pressure distribution. International Journal of Industrial Ergonomics, 35 (12), 1085-1096.

Porter, J. M., \& Gyi, D. E. (1998). Exploring the optimum posture for driver comfort. International Journal of Vehicle Design, 19 (3), 255-266.

Porter, J. M., Gyi, D. E., \& Tait, H. A. (2003). Interface pressure data and the prediction of driver discomfort in road trials. Applied Ergonomics, 34 (3), 207-214.

Sember, J. A. (1994). The biomechanical relationship of seat design to the human anatomy. In: Lueder, R., Noro, K., Eds. Hard Facts About Soft Machines: the Ergonomics of Seating. London: Taylor \& Francis, 221-251.

Søndergaard, K. H. E., Olesen, C. G., Søndergaard, E. K., De Zee, M., \& Madeleine, P., (2010). The variability and complexity of sitting postural control are associated with discomfort. Journal of Biomechanics, 43, 1997-2001.

Telfer, S., Spence, W. D., Solomonidis, S. E. (2009). The potential for actigraphy to be used as an indicator of sitting discomfort. Human Factors, 51 (5), 694-704.

Zenk, R., Franz, M., Bubb, H., \& Vink, P. (2012). Technical note: spine loading in automotive seating. Applied Ergonomics, 43 (2), 290-295. 